\title{
The setae of the gill-cleaning mechanism in the soldier crab Mictyris guinotae Davie, Shih and Chan, 2010 (Decapoda: Brachyura: Mictyridae)
}

\author{
Takashi Matsuoka, Hiroshi Suzuki and Miguel Vazquez Archdale
}

\begin{abstract}
The setae involved in gillcleaning in the soldier crab Mictyris guinotae were examined using a light microscope and an environmental scanning electron microscope. The setae of the epipods of the first and third maxillipeds are classified into three types: 1 ) anchor setae, 2) digitate-scale-setule setae, and 3) denticulate setae. The second maxillipeds lack epipods, and this absence can be explained in relation to the presence of the cup-shaped basal part of the third maxilliped epipod. The presence of anchor setae in $M$. guinotae may support the hypothesis that anchor setae are a brachyuran synapomorphy. The full anchor form may result from a fusing of the denticules on denticulate setae. The presence of digitate-scale-setule setae in $M$. guinotae may confirm that digitate-scalesetule setae are the ancestral character.
\end{abstract}

\section{Introduction}

Respiration in decapods requires a constant flow of water across the gills. This can lead to problems with suspended particulate debris, and the intake of potential gill epibionts. To solve this problem, decapods have developed mechanisms to protect their gills from fouling. Several researchers have studied the gill-cleaning mechanisms of brachyuran crabs (Bauer, 1981, 1989; Holmquist, 1989; Pohle, 1989; Batang \& Suzuki, 2003; Matsuoka \& Suzuki 2011; Matsuoka et al., 2011) and have suggested that they clean their gills with the setae on the epipods of the first to third maxillipeds (EpMp1-EpMp3).
Soldier crabs (Family Mictyridae) inhabit the intertidal zone and play an important ecological role in maintaining the proper functioning of the intertidal flats where they occur (Quinn, 1986; Dittman, 1994; Webb $\&$ Eyre, 2004). These crabs belong to one of the eight families in the Superfamily Ocypodoidea. The family Mictyridae contains a single genus Mictyris and seven species (Davie et al., 2010; Unno \& Semeniuk, 2011). Of these species, only Mictyris guinotae Davie, Shih and Chan, 2010, is found in Japan. The mictyrids differ greatly from other ocypodid crabs in overall shape and lifestyle, and they therefore occupy a unique position within the superfamily Ocypodoidea. The gillcleaning setae of species in the Ocypodidae and Macrophthalmidae have been described previously (Matsuoka \& Suzuki, 2011; Matsuoka et al., 2011). Detailed knowledge of the gill-cleaning setae of the family Mictyridae will help to further understand the gill-cleaning mechanisms of brachyuran crabs, including the Ocypodoidea, and more generally may assist in understanding evolutionary patterns and phylogenetic relationships within the brachyurans.

\section{Materials and Methods}

Mictyris guinotae specimens were captured from tidal flats on Amami-Ohshima Island, the Ryukyu Archipelago, southern Japan $\left(28^{\circ} 17^{\prime} \mathrm{N}, 129^{\circ} 22^{\prime} \mathrm{E}\right)$ in August 2007. One adult male specimen was fixed in $10 \%$ formalin and then preserved in 70\% ethyl alcohol $(\mathrm{EtOH})$. The specimen was dissected to examine EpMp1 to EpMp3 with an 

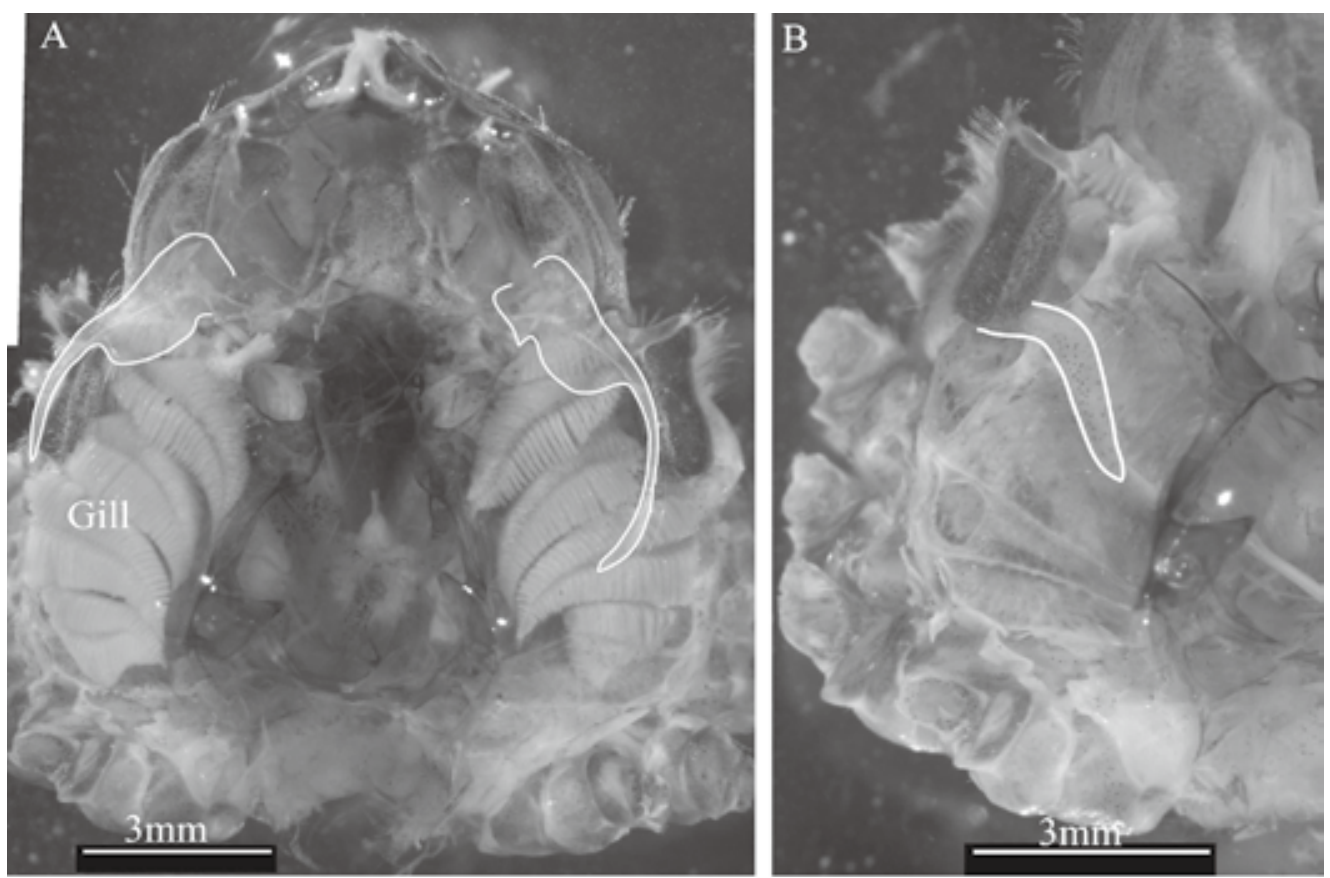

Fig. 1. Mictyris guinotae: dorsal view after removal of the carapace. A, location of epipods of first maxilliped; B, location of epipod of third maxilliped (gills removed). White lines show the outline of epipods.
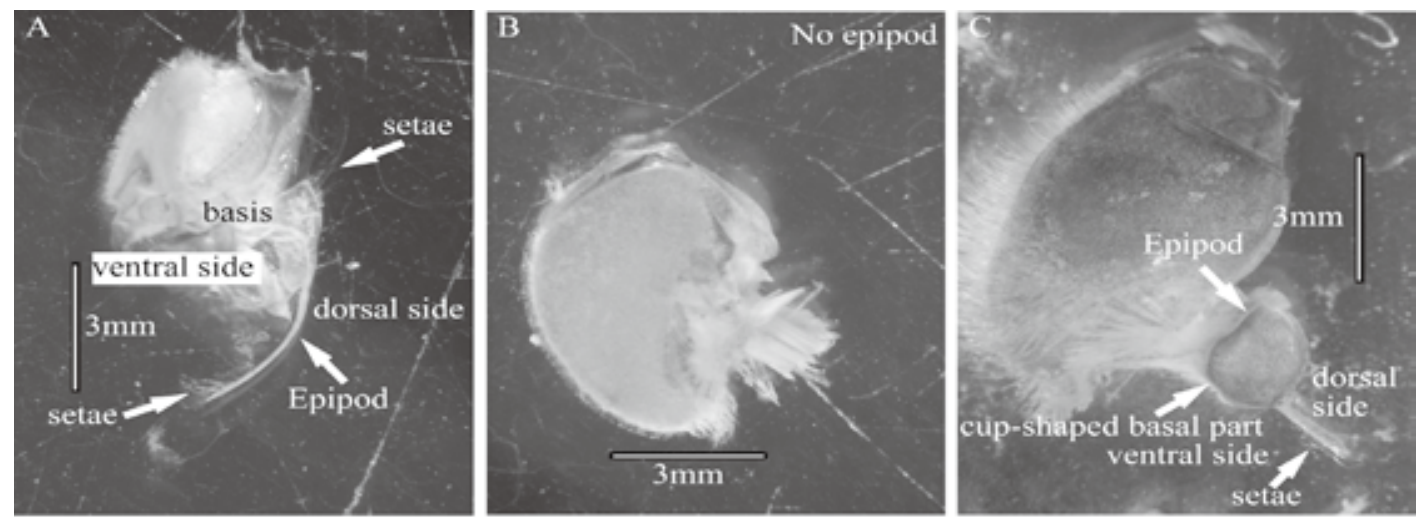

Fig. 2. Mictyris guinotae: ventral views of first to third maxillipeds. A, first maxilliped; B, second maxilliped; C, third maxilliped.

environmental scanning electron microscopy (ESEM, Japan FEI XL30, FEI Japan, Tokyo, Japan) and light microscopy (Nikon type 104, Nikon Co. Ltd. Tokyo, Japan). The dissected parts were photographed using a digital camera system (DIGITAL SIGHT, Nikon Co. Ltd. Tokyo, Japan). The specimen was dehydrated for at least 2 hours following an
EtOH series $(70 \%, 80 \%, 90 \%, 95 \%, 100 \%$ and $100 \%$ ), and then air-dried. The specimen was mounted on aluminum stubs, coated with gold with an Eiko ION COATER IB-2 and viewed with Japan FEI XL30.

Results 


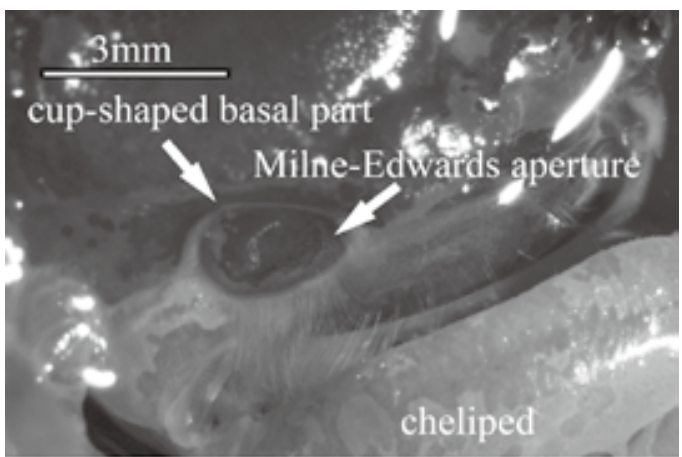

Fig. 3. Mictyris guinotae: frontal view of left MilneEdwards aperture (MEA). MEA is sealed by cupshaped basal part of the epipod of third maxilliped.

The EpMp1s were located on the dorsal side of the gills (Fig. 1A), whereas the EpMp3s were located beneath the gills (Fig. 1B). EpMp2 was absent. Setae were present on both EpMp1 and EpMp3 (Fig. 2). EpMp3 has a cup-shaped basal part (Figs. 2C, 3). The Milne-Edwards aperture (MEA) was sealed tightly by the cup-shaped basal part of the EpMp3 (Figs. 2C, 3). The setae on the epipods were classified into three types: digitate-scale-setule setae (DSSS), anchor setae, and denticulate setae (DS). Distally all three types of setae were armed with serrate-shaped denticules (Fig. 4D). One type of anchor setae was found in M. guinotae. Anchor setae were the dominant setae on EpMp1 and were the second most abundant setae on EpMp3. The anchor setae were of a full anchor type, with two recurved hooks joined back to back and facing opposite directions (Fig. 4C, E). The anchor setae were equipped with normal setules (Fig. 4C, E). On EpMp1, the anchor setae were located only near the base of the dorsal side. On EpMp3, the anchor setae were located all along the dorsal side. On EpMp1, the DSSS with distal serrate-shaped denticules (Fig. 4A, $\mathrm{B}, \mathrm{D})$ were the second most abundant type, and were located on the long, thin part of the epipod (Fig. 2A). On EpMp3, the DSSS with distal serrate-shaped denticules (Fig. 4A, $\mathrm{B}, \mathrm{D})$ were dominant and could be located on the ventral side (Fig. 2C). The DS were found only at the base of the dorsal side of EpMp1 (Fig. 2A) and were the third most abundant type. The DS were equipped with normal setules (Fig. 4F, G). Distally the DS were serrate-shaped denticules (Fig. 4D). The denticules were arranged in the similar form of a full anchor (Fig. 4G).

\section{Discussion}

Most ocypodid crabs inhabit intertidal areas and retain water within their branchial chambers for respiration when they are exposed to air. Maitland (1990) described the respiratory watercirculation and water-uptake mechanisms of Heloecius cordiformis (H. Milne Edwards, 1837). Some ocypodid crabs are able to replenish water supplies from substratum surface water. They can continue to respire on land by circulating water within the branchial chamber. The water then leaves the exhalant apertures, flowing down and out over the pterygostomial region of the branchiostegite. Water returns to the branchial chambers via an aperture termed the MilneEdwards aperture (MEA) (see Matsuoka \& Suzuki, 2011; Fig.1) located at the base of the chelipeds.

In M. guinotae, the MEA was sealed tightly by the cup-shaped basal part of the EpMp3. Therefore, water containing particulate debris is mostly prevented from entering the branchial chamber. In other crabs, however, the MEA is always open and this allows water with suspended particulate water to easily enter the branchial chamber. Therefore, the crabs must clean the mesial side of the gills with the EpMp2 located at the entrance of the MEA. However, in the case of $M$. guinotae it is assumed that, because the cupshaped basal part tightly seals the MEA, there is no need for an EpMp2 for cleaning. Anchor setae with their opposing recurved ends may have a high scraping efficiency and help clean and prevent the breakage of other setae, as noted in pinnotherids (Pohle, 1989). It is probable that the anchor setae serve the same function in portunids and xanthids (Batang \& Suzuki, 2003; Matsuoka \& Suzuki, 2011; Matsuoka et al., 2011). Anchor setae were also found on the epipods of the first and third maxillipeds of M. guinotae. Anchor setae seem to occur only in brachyuran crabs (Pohle, 1989; Matsuoka \& Suzuki, 2011), and this led Matsuoka \& Suzuki (2011) to suggest that anchor setae might be a synapomorphy of the Brachyura. The presence of anchor setae 

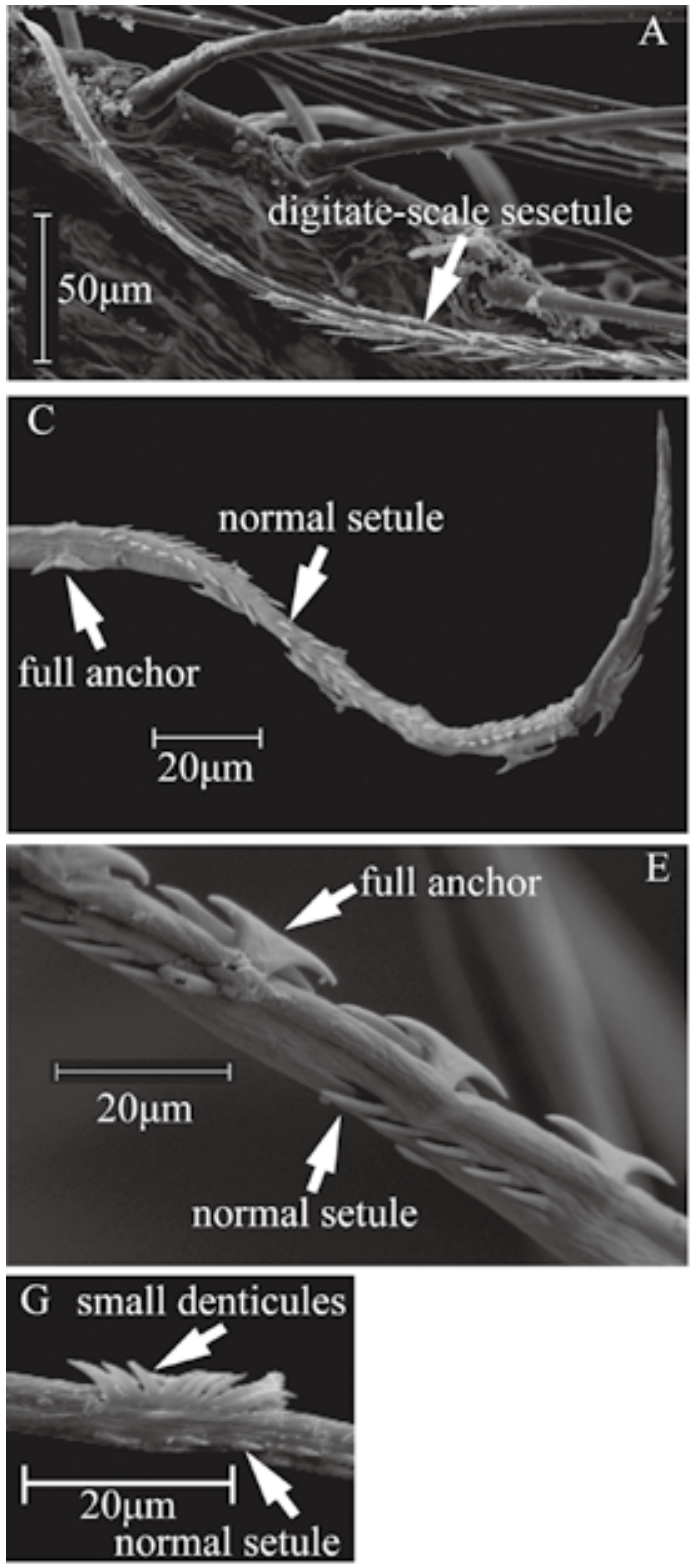
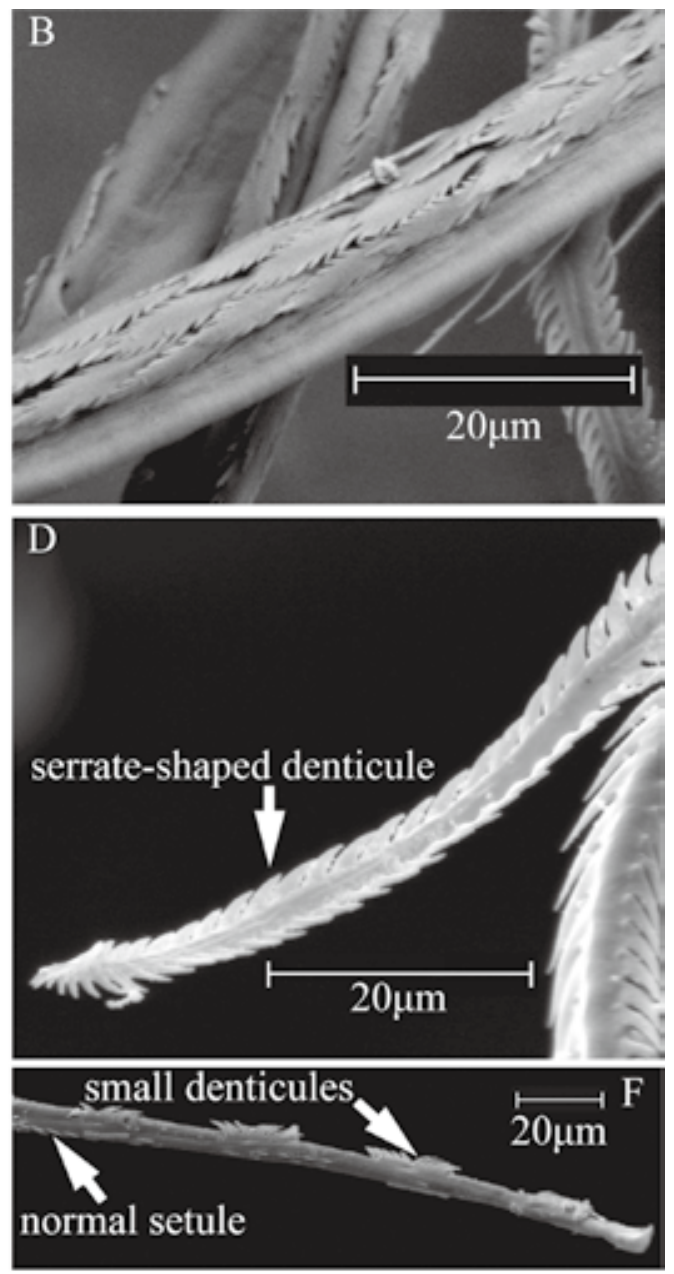

Fig. 4. Mictyris guinotae: setae on the epipod of first to third maxilliped. A, digitate-scale-setule seta with distal serrate-shaped denticules; B, close-up of the digitate-scale setules; C, full anchor seta with normal setules and distal serrate-shaped denticules; D, close-up of the distal part of full anchor seta with normal setules and distal serrate-shaped denticules; E, close-up of the normal setules of full anchor seta with normal setule and distal serrate-shaped denticules; F, denticulate seta with normal setules and distal serrate-shaped denticules. Denticles arranged like anchor; $\mathrm{G}$, close-up of the denticules and normal setules on seta in F.

in M. guinotae adds additional support for this hypothesis

The denticulate setae observed here in $M$. guinotae have not been reported by previous gill-cleaning studies in ocypodoids or other brachyurans generally (Bauer, 1989; Holmquist, 1989; Pohle, 1989; Batang \& Suzuki, 2003; Matsuoka \& Suzuki 2011; Matsuoka et al., 2011). The small denticules found in the denticulate setae (DS) of EpMp1 were arranged in a pattern 
resembling a full anchor (Fig. 4E). Furthermore, we propose that this full anchor form might have resulted from a fusing of these denticules.

The digitate-scale-setule setae are found from dendrobranchiates to brachyurans (Bauer, 1979, 1989, 1998, 1999; Batang \& Suzuki, 1999, 2000; Batang et al., 2001; Pohle, 1989; Suzuki \& McLay, 1998; Matsuoka \& Suzuki, 2011; Matsuoka et al., 2011); and are again reported here for M. guinotae. Therefore, we consider that the digitate-scale-setule setae are most likely to be the ancestral (plesiomorphic) character state.

\section{Acknowledgements}

We are very grateful to anonymous reviewers for their insightful comments on the manuscript. We are also grateful to Ms. Yuko Matsushima and Mr. Mitsuaki Watanabe for helping to collect data for this study. We thank the Division of Instrumental Analysis, Frontier Science Research Center, Kagoshima University.

\section{Literature Cited}

Batang, Z. B., \& Suzuki, H., 1999. Gillcleaning mechanisms of the mud lobster Thalassina anomala (Decapoda, Thalassinides, Thalassinidae). Journal of Crustacean Biology, 19: 671-683.

- \&,- 2000 . Gill structure and gill-cleaning mechanisms of the redclaw crayfish Cherax quadricarinatus (Decapoda, Astacidea, Parastacidae). Journal of Crustacean Biology, 20: 699714.

leaning mechanisms of the amphibious freshwater crab Geothelphusa dehaani (Decapoda, Brachyura, Potamidae). Journal of Crustacean Biology, 23: 230-240.

Batang, Z. B., Suzuki, H., \& Miura, T., 2001. Gill-cleaning mechanisms of the burrowing mud shrimp Laomedia astacina (Decapoda, Thalassinidea, Laomediidae). Journal of Crustacean Biology, 21: 873884.

Bauer, R. T., 1979. Antifouling adaptations of marine shrimp (Decapoda: Caridea): gill cleaning mechanisms and grooming of brooded embryos. Zoological Journal of the Linnean Society, 65: 181-303.

, 1981. Grooming behavior and morphology in the decapod Crustacea. Journal of Crustacean Biology, 1: 153173.

, 1989. Decapod crustacean grooming: functional morphology, adaptive value, and phylogenetic significance. In: B. E. Felgenhauer et al., (eds.), Functional Morphology of Feeding and Grooming in Crustacea, Crustacean Issues, Volume 6, A. A. Balkema, Rotterdam, pp. 49-73.

_ 1998. Gill-cleaning mechanisms of the crayfish Procambarus clarkii (Astacidea: Cambaridae): experimental testing of setobranch function. Invertebrate Biology, 117: 129-143.

, 1999. Gill-cleaning mechanisms of dendrobranchiate shrimp, Rimapenaeus similis (Decapoda, Penaeidae): description and experimental testing of function. Journal of Morphology, 242: 125-139.

Davie, P. J. F., Shih, H. T., \& Chan, B. K. K., 2010. A new species of Mictyris (Decapoda, Brachyura, Mictyridae) from the Ryukyu Islands, Japan. In: P. Castro et al., (eds.), Studies on Brachyura : a Homage to Danièle Guinot, Crustaceana Monographs, Volume 11, Brill, Leiden, pp. 83-105.

Dittmann, S., 1994. Impact of foraging soldier crabs (Decapoda: Mictyridae) on meiofauna in a tropical tidal flat. Revista de Biología Tropical, 41: 627-637.

Holmquist, J., 1989. Grooming structure and function in some terrestrial Crustacea. In: B. E. Felgenhauer et al., (eds.), Functional Morphology of Feeding and Grooming in Crustacea, Crustacean Issues, Volume 6, A. A. Balkema, Rotterdam, pp. 95-112.

Maitland, D. P., 1990. Carapace and branchial water circulation, and waterrelated behaviours in the semaphore crab Heloecius cordiformis (Decapoda: Brachyura: Ocypodidae). Marine Biology, 105: 275-286.

Matsuoka, T., \& Suzuki, H., 2011. Setae for gill-cleaning and respiratory-water circulation of ten Japanese ocypodid crabs. Journal of Crustacean Biology, 31: 9-25.

Matsuoka, T., Suzuki, H., \& Vazquez 
Archdale, M., 2011. Setae for gill-cleaning of six species of Japanese sentinel crabs (Macrophthalmus). Journal of Crustacean Biology. 31: 598-605.

Pohle, G., 1989. Structure, function, and development of setae on gill-cleaning appendages and associated mouthparts of pinnotherid crabs (Decapoda: Brachyura). Canadian Journal of Zoology, 67: 16901707.

Quinn, R. H., 1986. Experimental studies of food ingestion and assimilation of the soldier crab, Mictyris longicarpus Latreille (Decapoda, Mictyridae). Journal of Experimental Marine Biology and Ecology, 102: 167-181.

Suzuki, H., \& McLay, C, L., 1998. Gillcleaning mechanisms of Paratya curvirostris (Caridea, Atyidae) and comparisons with seven species of Japanese atyid shrimps. Journal of Crustacean Biology, 18: 253-270.

Unno, J., \& Semeniuk, V., 2011. A new species of Mictyris (Crustacea: Decapoda: Brachyura: Mictyridae) recorded from northern Australia - Kimberley region to
Cape York. Journal of the Royal Society of Western Australia, 94: 45-54.

Webb, A. P., \& Eyre, B. D., 2004. The effect of natural populations of the burrowing and grazing soldier crab (Mictyris longicarpus) on sediment irrigation, benthic metabolism and nitrogen fluxes. Journal of Experimental Marine Biology and Ecology, 309: 1-19.

Address: (TM) United Graduate School of Agricultural Sciences, Kagoshima University, 1-21-24 Korimoto, Kagoshima 890-0065, Japan; (HS) (MVA) Faculty of Fisheries, Kagoshima University, 4-50-20 Shimoarata, Kagoshima 890-0056, Japan.

E-mail: (TM) k2216439@kadai.jp; (HS) suzuki@fish.kagoshima-u.ac.jp; (MVA) miguel@fish.kagoshima-u.ac.jp

Received: 17 August 2011.

ACCEPTED: 2 December 2011. 